\title{
PENYULUHAN PENGGUNAAN LISTRIK DARI SUMBER ENERGI SURYA DI PESANTREN AL MUKARRAMAH KABUPATEN BANDUNG
}

\author{
${ }^{1}$ Ekki Kurniawan, ${ }^{2}$ Wahmisari Priharti, ${ }^{3}$ Desri Kristina Silalahi \\ ${ }_{1,2,3}$ Universitas Telkom, Bandung, Indonesia. \\ e-mail: ${ }^{1}$ ekkikurniawan@telkomuniversity.ac.id, ${ }^{2}$ wpriharti@telkomuniversity.ac.id, \\ ${ }^{3}$ desrikristina@telkomuniversity.ac.id
}

\begin{abstract}
Al Mukarramah Boarding School is located in Bandung Regency, West Java Province. The total land area owned by this boarding school is $3000 \mathrm{~m}^{2}$ (three thousand square meters) consisting of several spaces and buildings. PLN is the main electricity source for lighting in this schools with a total power of $4400 \mathrm{VA}$ and costs an average of $R p .3,000,000.00$ per month. This cost is certainly quite burdensome since not all santri are well-off to pay education coaching contributions (SPP) as a source of monthly operational costs. Therefore, efforts to reduce the costs borne by this school through alternative electricity sources need to be done. This was carried out in Community Service (PKM) through the installation of a simple Solar Power Plant. Counseling on how the PLTS works and the maintenance technique of PLTS is also provided so that PLTS can work well and can last a long time.
\end{abstract}

Keywords: Renewable energy, solar energy, Al Mukarramah Boarding School.

\begin{abstract}
Abstrak. Pesantren Al Mukarramah terletak di Kabupaten Bandung, Provinsi Jawa Barat. Luas tanah yang dimiliki pesantren ini sekitar $3000 \mathrm{~m}^{2}$ (tiga ribu meter persegi) yang terdiri dari beberapa ruang dan bangunan. Sumber listrik utama bagi penerangan di pesantren saat ini berasal dari PLN dengan total daya 4400 VA dan menghabiskan biaya rata-rata $R p$ 3.000.000,00 per bulan. Biaya sebesar ini tentunya cukup memberatkan sebab tidak semиa santri berkecukupan untuk membayar sumbangan pembinaan pendidikan (SPP) sebagai sumber biaya operasional bulanan. Oleh karena itu, upaya untuk meringankan biaya yang ditanggung pesantren melalui sumber energi listrik alternatif perlu dilakukan. Hal ini dilaksanakan dalam Pengabdian Kepada Masyarakat (PKM) melalui pemasangan Pembangkit Listrik Tenaga Surya sederhana. Penyuluhan tentang cara kerja dan teknik pemeliharaan PLTS ini juga diberikan agar PLTS dapat bekerja dengan baik dan bertahan lama.

Kata Kunci: Energi terbarukan, pembangkit listrik tenaga surya, Pesantren Al Mukarramah.
\end{abstract}

\section{Pendahuluan}

Pesantren Al Mukarramah (AM) di bawah naungan pembinaan Yayasan Al Mukarramah terletak di Desa Padasuka, Kecamatan Cimenyan, Kabupaten Bandung, Jawa Barat. Pesantren ini telah berdiri sejak 11 September 1979. Luas tanah yang dimiliki pesantren ini sekitar $3000 \mathrm{~m}^{2}$ (tiga ribu meter persegi). Di samping kegiatan kepesantrenan, Yayasan AM membuat sekolah formal berbadan hukum resmi yaitu kelompok bermain (kober), taman kanak kanak (TK) dan sekolah menengah pertama (SMP). Jumlah peserta didik di pesantren ini kurang lebih sebanyak 120 orang putraputri yang berasal dari masyarakat setempat dan juga dari luar daerah. Sedangkan jumlah guru dan tenaga pendidik di pesantren ini sebanyak 16 orang.

Saat ini pesantren AM memiliki beberapa ruang dan gedung, yaitu masjid 
bergabung dengan ruang kober-TK, enam buah kelas, ruang kantor kepala sekolah, ruang guru, ruang komputer, asrama putra, asrama putri, perpustakaan, ruang olah raga, ruang kesenian, dapur, dan ruang mandi-cucikakus (MCK). Ruangan-ruangan ini tentunya memerlukan sumber listrik yang memadai untuk penerangan maupun keperluan lainnya.

Sumber listrik yang digunakan pesantren saat ini berasal dari PLN. Terdapat dua kWhmeter PLN yang dipasang di pesantren ini, yaitu di masjid dan di kantor kepala sekolah. Kapasitas arus Miniature Circuit Breaker (MCB) masing-masing kWhmeter ini adalah 10 Ampere, 220 Volt, sehingga total daya maksimum yang dapat dipakai sebesar 4400 VA $(2 \times 2200$ VA). Walaupun demikian keandalan PLN ini dirasa masih kurang karena sering kali terjadi pemutusan dan drop tegangan akibat lokasi pesantren terletak jauh dari gardu PLN. Pemutusan berulang ini mengakibatkan gangguan untuk beban emergensi serta beban-beban yang penting dan mendesak, misalnya server komputer. Selain itu, sistem penerangan gerbang depan serta penerangan taman di pesantren juga belum memadai.

Masalah lain yang dihadapi pesantren adalah biaya penggunaan listrik yang cukup besar sehingga mencapai rata-rata $\mathrm{Rp} 3.000 .000$,- (tiga juta rupiah) tiap bulan. Biaya sebesar ini tentu sangat memberatkan, sebab tidak semua santri berkecukupan untuk membayar sumbangan pembinaan pendidikan (SPP) sebagai sumber biaya operasional bulanan. Selain itu, ketergantungan pada listik PLN yang sangat besar ini dapat mengakibatkan bertambahnya pemanasan global, karena sumber energi yang digunakan PLN saat ini masih bersifat konvensional.

Untuk mengatasi masalahmasalah tersebut, kegiatan Pengabdian Kepada Masyarakat (PKM) yang berfokus terhadap penyuluhan penggunaan listrik dari sumber energi surya telah dilakukan. Energi surya dipilih sebagai sumber energi listrik alternatif karena jumlahnya yang melimpah dan tersedia secara cumacuma, bebas gangguan dan polusi, serta mudah dalam pemasangan dan perawatannya (CEI, 2010). Alat yang digunakan sebagai penghasil energi adalah panel surya yang merupakan gabungan dari beberapa sel surya.

Sel surya merupakan suatu piranti yang dapat merubah cahaya mahatari menjadi listrik secara langsung melalui efek fotovoltaik. Piranti ini terbuat dari bahan semikonduktor silikon yang terdiri dari dua jenis, yaitu jenis $n$ dan p. Semikonduktor jenis $n$ memiliki kelebihan elektron sehingga bermuatan negatif, sedangkan semikonduktor jenis p memiliki kelebihan hole sehingga bermuatan positif (Kalogirou, 2018). Silikon merupakan bahan yang mudah diubah konduktifitasnya dengan cara menambahkan pengotor (dopant) ke dalam kisi kristal $\mathrm{n}$ dan $\mathrm{p}$ ini. Peningkatan konduktifitas ini meningkatkan daya hantar panas atau listrik dari sebuah semikonduktor (EC, 2009)

Dua jenis semikonduktor jenis $n$ dan $\mathrm{p}$ ini ketika disatukan akan membentuk sambungan p-n (p-n junction) yang dipisahkan oleh suatu lapisan deplesi (depletion layer). Pada sel surya, semikonduktor jenis $\mathrm{n}$ berada pada lapisan yang menghadap ke arah datangnya cahaya matahari, dan dibuat jauh lebih tipis dari semikonduktor jenis 
$\mathrm{p}$, sehingga cahaya matahari yang jatuh ke permukaan sel surya dapat terus terserap dan masuk ke lapisan deplesi dan semikonduktor jenis p. Ketika sambungan $\mathrm{p}-\mathrm{n}$ ini terkena cahaya matahari, maka elektron mendapat energi dari cahaya matahari untuk melepaskan dirinya dari semikonduktor jenis $n$ sehingga meninggalkan hole pada daerah yang ditinggalkan oleh elektron tersebut. Fenomena ini disebut fotogenerasi elektron-hole (electronhole photogeneration). Karena pada sambungan p-n terdapat medan listrik E, elektron hasil fotogenerasi tertarik ke arah semikonduktor jenis n, begitu pula dengan hole yang tertarik ke arah semikonduktor jenis p. Apabila rangkaian kabel dihubungkan ke dua bagian semikonduktor ini, maka elektron akan mengalir melalui kabel. Jika sebuah lampu kecil dihubungkan ke kabel, lampu tersebut menyala dikarenakan mendapat arus listrik, dimana arus listrik ini timbul akibat pergerakan elektron (Wibowo, 2008). Fenomena ini ditunjukkan pada Gambar 1 (Hersch \& Zweibel, 1982).

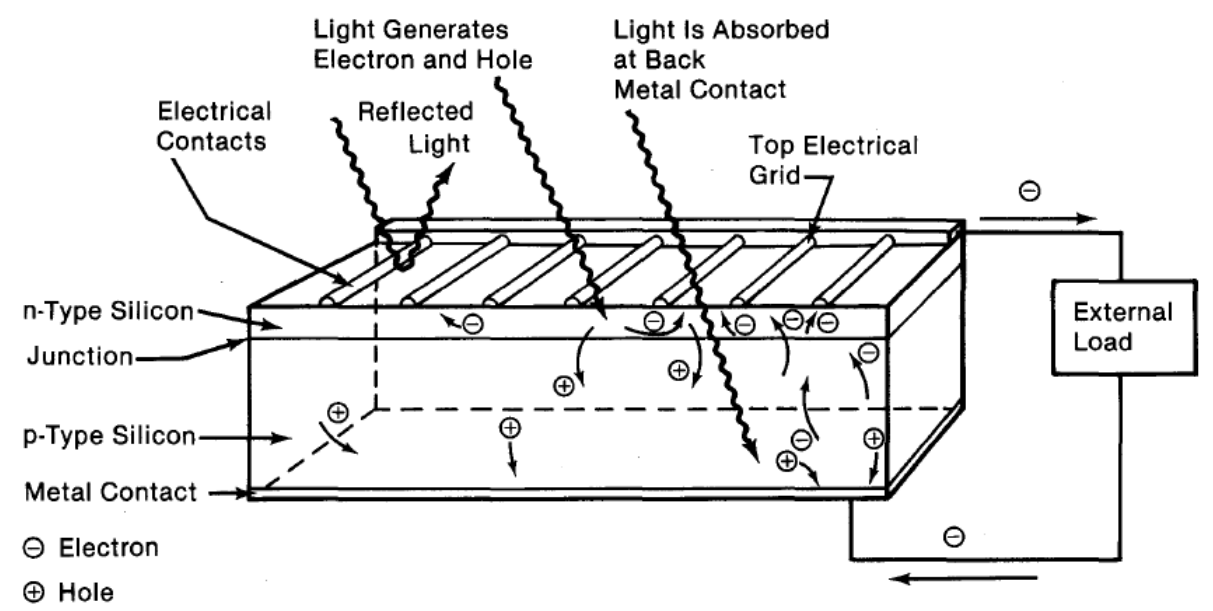

Gambar 1. Proses perubahan cahaya menjadi listrik pada sel surya (fotovoltaik)

Kegiatan PKM ini bertujuan untuk memberikan pengetahuan dan pemahaman di kalangan masyarakat pesantren dan sekitarnya mengenai pemasangan sistem Pembangkit Listrik Tenaga Surya (PLTS). Sistem PLTS yang dipasang pada pesantren ini meliputi panel surya, baterai, alat monitoring tegangan dan arus, saklar, stop kontak, lampu-lampu light emmiting diode (LED) dan pelengkap lainnya. Panel surya akan mengalirkan energi menuju baterai pada siang hari, kemudian energi pada baterai digunakan pada malam hari atau ketika ketiadaan matahari. Lampu dapat dinyalakan secara otomatis maupun manual menggunakan saklar. Untuk memudahkan pemantauan, Power House atau Pusat Daya PLTS dipasang di sekitar masjid dan di dekat ruang kepala sekolah. Agar PLTS dapat bertahan lama, maka diperlukan pengetahuan tentang teknik penggunaan dan pemeliharaannya. Oleh karena itu pada kegiatan PKM ini juga dilakukan penyuluhan-penyuluhan yang berkaitan dengan penggunaan dan pemeliharaan PLTS tersebut.

Pemasangan PLTS di pesantren AM melalui kegiatan PKM ini diharapkan dapat memberikan manfaat bagi masyarakat sasar di pesantren tersebut, antara lain mengurangi biaya 
listrik bulanan jangka panjang, mengurangi ketergantungan pada listrik PLN, menghindari gangguan untuk beban emergensi dan beban-beban yang penting dan mendesak, serta membantu mengurangi pemanasan global karena sistem PLTS yang ramah lingkungan.

\section{Metode Penelitian}

Kegiatan PKM ini terdiri dari beberapa langkah yaitu Survei lapangan yang lebih detail untuk mengetahui situasi di pesantren Al Mukarramah. Dari hasil survei diketahui bahwa penerangan pada beberapa lorong, gerbang depan dan taman pesantren masih belum memadai.
Konsolidasi tim pelaksana PKM. Kegiatan PKM ini selain dilaksanakan oleh dosen juga melibatkan beberapa orang mahasiswa Fakultas Teknik Elektro, Universitas Telkom.

Pembelian peralatan dan bahanbahan serta pemasangan sistem PLTS. Pembelian peralatan serta pemasangan sistem melibatkan dosen dan juga mahasiswa yang tahapannya terdiri dari: pengujian peralatan di Universitas Telkom dan pemasangan alat yang telah teruji di Pesantren Al Mukarramah. Adapun daftar peralatan yang digunakan ditunjukkan pada Tabel 1 serta diagram sistem PLTS yang dipasang ditunjukkan oleh Gambar 2.

Tabel 1. Daftar peralatan yang digunakan pada PLTS

\begin{tabular}{|l|l|l|}
\hline Jenis Alat & Fungsi & Spesifikasi \\
\hline Panel Surya & $\begin{array}{l}\text { Alat yang mengubah cahaya } \\
\text { menjadi listrik }\end{array}$ & $\begin{array}{l}\text { Daya maksimum }\left(\mathrm{P}_{\max }\right): 50 \mathrm{~W} \\
\text { Tegangan pada } \mathrm{P}_{\max }\left(\mathrm{V}_{\mathrm{mp}}\right): 17,6 \mathrm{~V} \\
\text { Arus pada } \mathrm{P}_{\max }\left(\mathrm{I}_{\mathrm{mp}}\right): 2,85 \mathrm{~A}\end{array}$ \\
\hline Baterai & Tempat penyimpanan daya & $\begin{array}{l}\text { Jenis: Aki Industrial Lead Acid } \\
\text { Tegangan: 12 V } \\
\text { Arus: 35 Ah }\end{array}$ \\
\hline $\begin{array}{l}\text { Light Emitting } \\
\text { Diode (LED) }\end{array}$ & Beban lampu DC & $\begin{array}{l}\text { Daya: 7 dan 9 W } \\
\text { Tegangan: 12 V }\end{array}$ \\
\hline $\begin{array}{l}\text { Display Arus } \\
\text { dan Tegangan }\end{array}$ & $\begin{array}{l}\text { Alat pengukur dan pemantau } \\
\text { arus dan tegangan yang } \\
\text { dihasilkan panel surya }\end{array}$ & $\begin{array}{l}\text { Display arus: 0-10 A } \\
\text { Display tegangan: 0-100 V }\end{array}$ \\
\hline
\end{tabular}




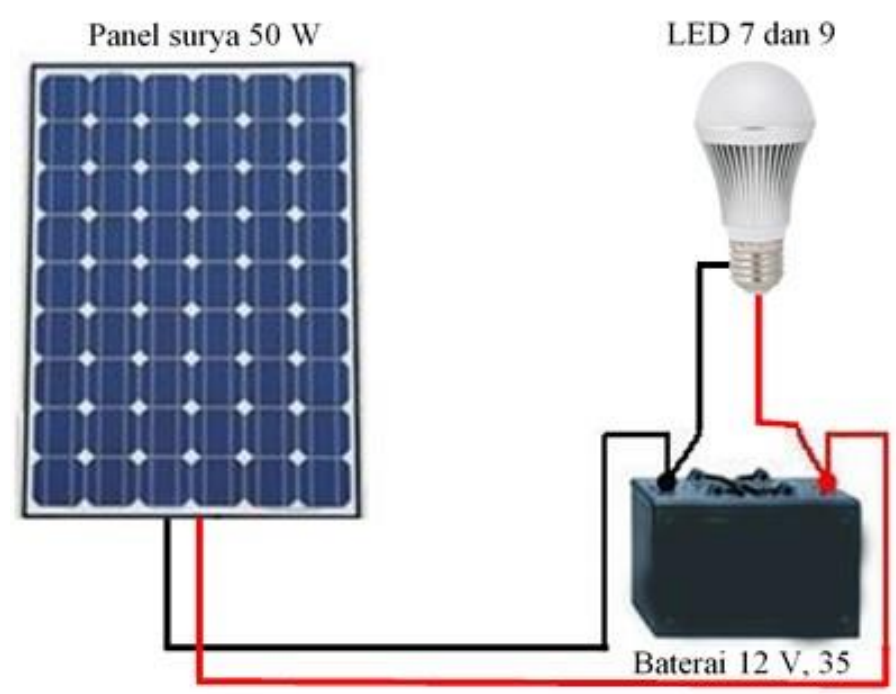

Gambar 2. Sistem PLTS yang dipasang

Penyuluhan tentang pemasangan dan perawatan PLTS kepada masyarakat sasar. Penyuluhan dilakukan secara lisan oleh ketua PKM yang meliputi definisi dan cara kerja dan spesifikasi panel surya, cara kerja sistem penyimpanan energi surya pada baterai, cara penyambungan dari panel surya ke baterai dan beban lampu penerangan, cara perawatan dan pemeliharaan panel surya dan baterai serta permasalahan (troubleshoot) yang mungkin terjadi pada sistem beserta cara penanggulangannya.

Pengujian dan pengukuran terhadap sistem PLTS yang sudah terpasang.

Partisipasi masyarakat sasar dalam kegiatan ini berjumlah kurang lebih 8 (delapan) orang yang terdiri guru dan masyarakat di sekitar lokasi pesantren. Hasil pelaksanaan kegiatan ini di evaluasi dari kuesioner yang diisi oleh masyarakat sasar tentang penyuluhan yang diperoleh. Parameter yang dinilai adalah bagaimana proses, tanggapan dan respon dari masyarakat sasar.

\section{Hasil dan Pembahasan}

\section{Daya yang dihasilkan oleh PLTS}

Daya riil yang terhasil dari sistem PLTS terpasang dapat dipantau melalui display arus dan tegangan. Daya yang dihasilkan oleh panel surya dapat digunakan secara langsung untuk menyalakan beban lampu (LED) 7 dan 9 W. Pada malam hari atau ketika ketiadaan matahari, daya untuk menyalakan lampu diambil dari baterai. Besar daya yang dihasilkan dan serta lama penggunaannya dapat dilihat pada perhitungan berikut:

PLTS yang dipasang di Pesantren Al Mukarramah memiliki panel surya dengan daya maksimum 50 $\mathrm{W}, \mathrm{V}_{\mathrm{mp}} 17,6 \mathrm{~V}$ dan $\mathrm{I}_{\mathrm{mp}} 2,85 \mathrm{~A}$ dan baterai dengan kapasitas tegangan $12 \mathrm{~V}$ dan arus 35 Ah. Jika kita asumsikan bahwa matahari bersinar terik selama 6 jam/hari, maka waktu yang dibutuhkan panel surya untuk mengisi penuh baterai adalah selama 2 hari [35 Ah/(2,85A × 6 h)]. Total daya yang dapat disimpan dalam baterai (jika efisiensi dianggap $80 \%)$ adalah $336 \mathrm{Wh}(12 \mathrm{~V} \times 35 \mathrm{Ah} \times$ $80 \%$ ). Maka jika hanya menggunakan 
daya dari baterai, lampu 7 dan $9 \mathrm{~W}$ dapat menyala selama terus menerus selama 21 jam [336 Wh/(7 + 9)W]. Untuk menghemat energi, lampu hanya dinyalakan ketika malam hari dan ketika siang hari lampu akan dimatikan secara otomatis menggunakan sensor fotosel. Gambar 3 menunjukkan proses pemasangan panel surya pada PLTS di Pesantren Al Mukarramah.

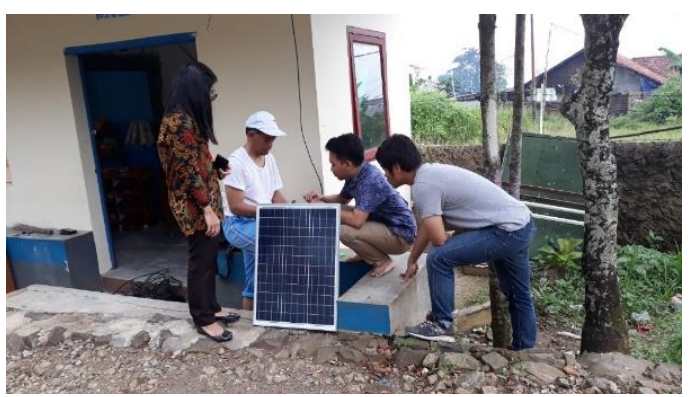

Gambar 3. Pemasangan PLTS di Pesantren Al Mukarramah

\section{Hasil kuesioner kegiatan penyuluhan}

Hasil pelaksaan penyuluhan pada kegiatan PKM ini dinilai sangat baik dan memuaskan, terbukti dari nilai kuesioner pada Gambar 4 yang mencapai 87,50 $93,75 \%$ untuk setiap butir penilaian. Selain itu, respon dan komentar yang diberikan masyarakat juga dinilai sangat baik bahkan mereka mendukung diadakannya kembali kegiatan-kegiatan seperti ini dengan jumlah peserta yang lebih ramai dan mencakup kawasan yang lebih luas lagi. Gambar 5 dan 6 menunjukkan suasana penyuluhan yang dihadiri oleh tim pelaksana dan masyarakat sasar.

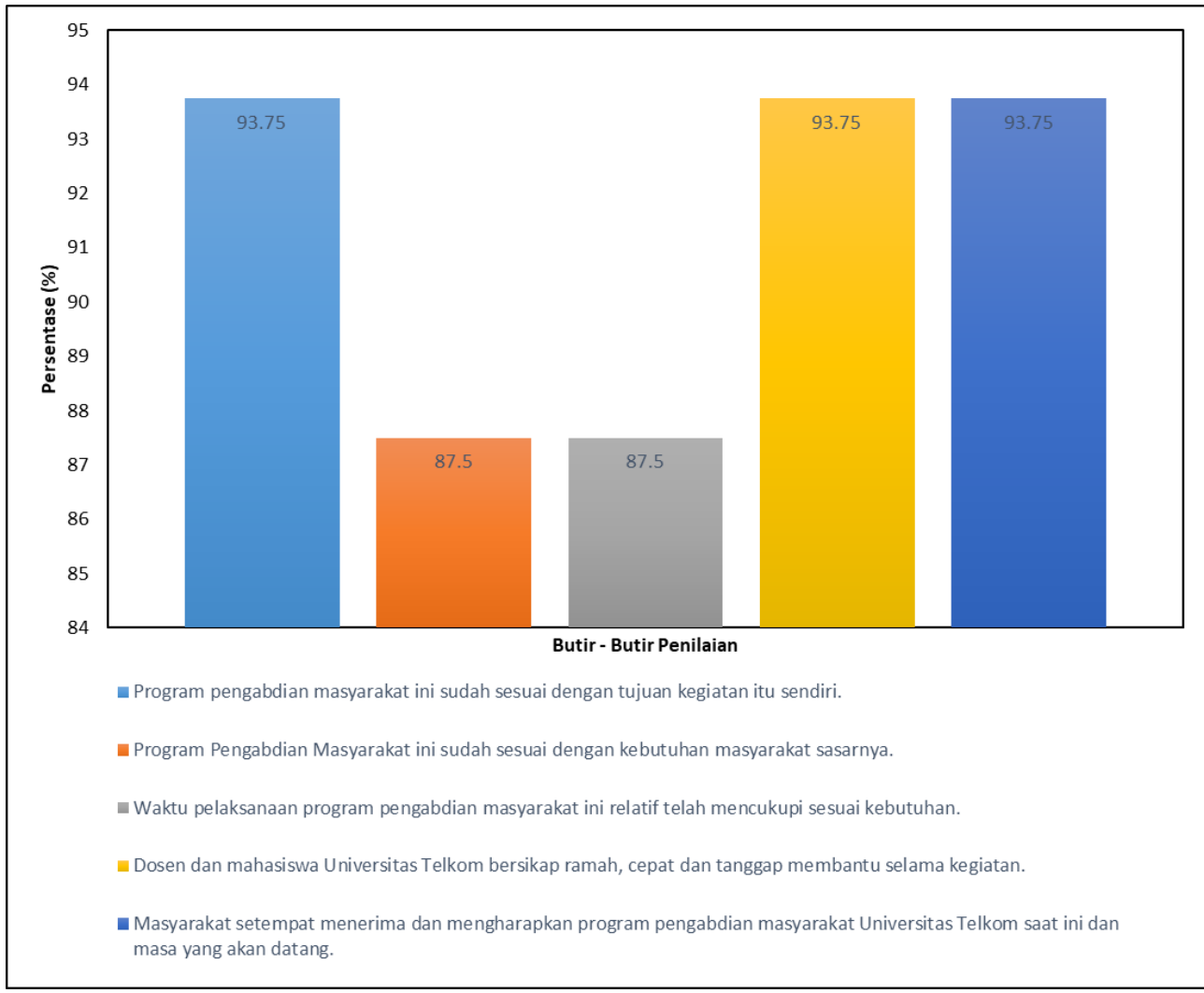

Gambar 4. Hasil kuesioner masyarakat sasar terhadap kegiatan penyuluhan PKM 


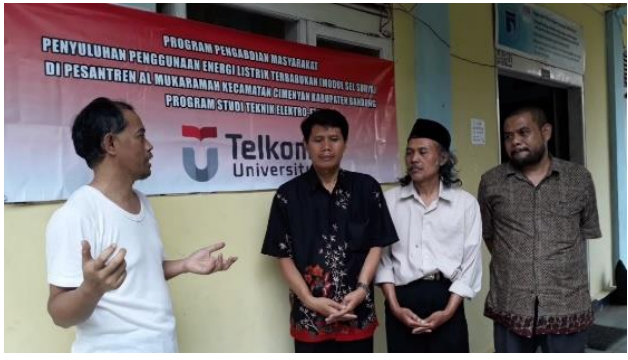

Gambar 5. Pemberian penyuluhan mengenai PLTS kepada masyarakat sasar

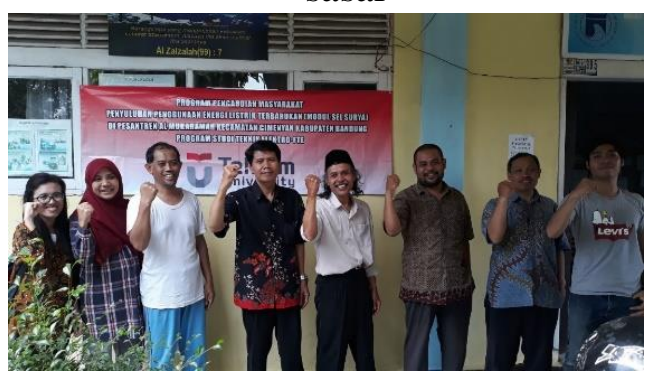

Gambar 6. Tim pelaksana Pengabdian Kepada Masyarakat bersama masyarakat sasar

\section{Kesimpulan dan Saran}

Pembangkit listrik tenaga surya (PLTS) merupakan sumber energi terbarukan yang relatif murah, mudah diaplikasikan dan dapat memberikan manfaat yang banyak kepada masyarakat. Masyarakat sasar di Pesantren Al Mukarramah sangat antusias mengikuti penyuluhan PLTS melalui kegiatan PKM ini, terbukti dari respon yang baik dan hasil kuesioner yang memuaskan. Diharapkan penyuluhan ini dapat menambah pengetahuan masyarakat tentang sumber energi terbarukan serta cara perawatan dan pemeliharaan PLTS yang telah terpasang.

\section{Ucapan Terimakasih}

Tim pelaksana Pengabdian Kepada Masyarakat (PKM) menyampaikan terima kasih kepada pihak Direktorat Penelitian dan Pengabdian Masyarakat Universitas Telkom yang telah membantu pendanaan dalam pelaksaan PKM ini. Selain itu, tim pelaksana juga mengucapkan terima kasih kepada pihak Pesantren Al Mukarramah atas kesediaan dan kerjasama yang baik sepanjang pelaksaan PKM.

\section{Daftar Pustaka}

European Commission (2009). "Photovoltaic Solar Energy: Development and Current Research", Luxembourg: European Communities.

Hersch, P. dan Zweibel, K. (1982). "Basic Photovoltaic Principles and Methods", Washington: Solar Energy Research Institute.

Kalogirou, S.A. (2018). 'McEvoy's Handbook of Photovoltaics: Fundamentals and Applications", Third edition, London: Academic Press.

Wibowo, R.A. (2008). Melihat prinsip kerja sel surya lebih dekat - Updated (Bagian Pertama). (https://energisurya.wordpress.com/ 2008/07/10/melihat-prinsip-kerjasel-surya-lebih-dekat/) diunduh pada 7 Mei 2018. 